\title{
BROAD LIGAMENT PREGNANCY: A CASE REPORT
}

Atima Bharti ${ }^{1}$, Aarti Jyoti², Diksha Ambedkar ${ }^{3}$

\section{HOW TO CITE THIS ARTICLE:}

Atima Bharti, Aarti Jyoti, Diksha Ambedkar. "Broad Ligament Pregnancy: A Case Report". Journal of Evolution of Medical and Dental Sciences 2014; Vol. 3, Issue 15, April 14; Page: 3872-3873,

DOI: $10.14260 /$ jemds/2014/2369

INTRODUCTION: Abdominal pregnancy is a rare but a life threatening condition which poses considerable challenge particularly to care providers in developing countries. Clinically it is difficult to diagnose. Sonography helps in early diagnosis but in unbooked cases it is diagnosed only during surgery.

Maternal mortality rate has been reported to be high as $20 \%$ in abdominal pregnancies. Broad ligament pregnancy is very rare. It is an acute emergency and may be misdiagnosed for rupture uterus. Ultrasonography may suggest the possibility if there is a high index of suspicion.

CASE REPORT: A 25-year-old $\mathrm{G}_{4} \mathrm{P}_{3+0}$ was admitted to RIMS labor room midnight on 19/08/13. She was referred from Sadar Hospital Ranchi, where laparotomy was done on suspicion of rupture uterus. Since no fetus was found in the peritoneal cavity with intact uterus, abdomen was closed and patient referred to RIMS.

Patient had history of massage by a local dai two days back. After massage she did not have labor pains so sent to Sadar Hospital. All her previous three deliveries were full term vaginal home deliveries. In present pregnancy she had no antenatal checkup, she did not know her LMP but according to her she was nine months pregnant. She never perceived any fetal movements. Her previous menstrual cycle was regular.

On general examination her general condition was poor her vitals were stable and had moderate pallor. Abdominal examination revealed vague tenderness all over the abdomen, globular firm mass felt in right lumbar region, fetal parts not felt superficially, FHS not heard. Pelvic examination revealed uneffaced undilated cervix with presenting part high up.

Ultrasonography reported a dead fetus with placenta lying outside the uterine cavity, fetal head just underneath liver. Uterine cavity was empty.

Exploratory laparotomy was done on 20/08/13.0n opening the peritoneal cavity there was no hemoperitoneum. Uterus was bulky and intact. Large globular mass was seen in right broad ligament. Incision was given in right broad ligament at the level of lower segment. A dead macerated fetus of 28 weeks was delivered by breech along with intact placenta.

There was absolutely no liquor. Right salpingectomy was done with tubal ligation on left side. Abdomen closed. Postoperative period was uneventful. Patient discharged on 27/08/13. 


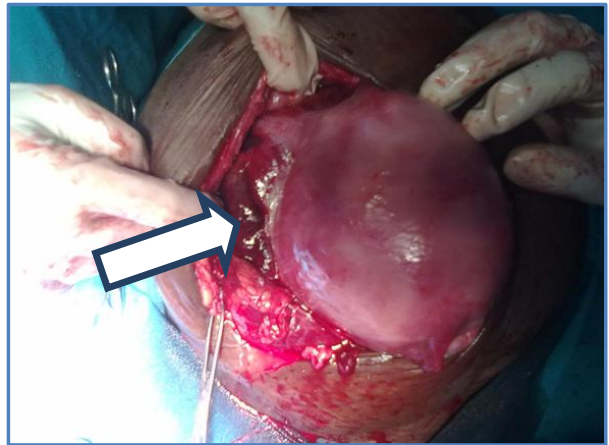

Fig. 1: Enlarged uterus with fetus in right broad ligament

DISCUSSION: Incidence of abdominal pregnancy with diagnosis of 1 per 10, 000 births is an extremely rare but life threatening situation. ${ }^{1}$ It is considered that it is more common in developing countries where incidence of pelvic inflammatory disease is more.

It is diagnosed late as antenatal care is inadequate. Mothers living in remote rural areas do not have a regular antenatal checkup so diagnosis is delayed and viable fetal outcome is a rare event. Diagnosis of abdominal pregnancies is missed even with routine ultrasonography examination. ${ }^{2}$

In a patient of amenorrhea, signs and symptoms of abdominal pain, gastrointestinal disturbances painful fetal movement, abnormal presentation, uneffaced cervix should arouse suspicion of abdominal pregnancy. Dull lower abdominal pain during early gestation is attributed to placental separation, broad ligament tear and small peritoneal hemorrhage.

\section{REFERENCES:}

1. Ludung M, Kaisim, Bauer O, Diedrich K. The Forgotten Child-a case of heterotopic, intraabbominal and intrauterine pregnancy carried to term. Ham Reprod 1999; 14: 1372-4.

2. White R G. Advanced Abdominal Pregnancy-a review of 23 cases. Iran J Med Sci 1989; 158: 778.

\section{AUTHORS:}

1. Atima Bharti

2. Aarti Jyoti

3. Diksha Ambedkar

\section{PARTICULARS OF CONTRIBUTORS:}

1. Assistant Professor, Department of Obstetrics and Gynaecology, Rajendra Institute of Medical Sciences, Ranchi.

2. Senior Resident, Department of Obstetrics and Gynaecology, Rajendra Institute of Medical Sciences, Ranchi.

3. Junior Resident, Department of Obstetrics and Gynaecology, Rajendra Institute of Medical Sciences, Ranchi.

\section{NAME ADDRESS EMAIL ID OF THE CORRESPONDING AUTHOR: \\ Dr. Atima Bharti, Department of Obstetrics and Gynaecology, RIMS, Ranchi. \\ E-mail: dratimabharti@gmail.com}

